\title{
A "solution-focused" comparative risk assessment of conventional and synthetic biology approaches to control mosquitoes carrying the dengue fever virus
}

\author{
Adam M. Finkel ${ }^{1,2} \cdot$ Benjamin D. Trump 2 - Diana Bowman³ $\cdot$ Andrew Maynard $^{4}$ \\ Published online: 14 May 2018 \\ (c) Springer Science+Business Media, LLC, part of Springer Nature 2018
}

\begin{abstract}
Emerging technologies often pose various uncertain health risks that cause policymakers to hesitate to allow resultant products and processes to enter the market—but they also may offer large benefits, including the potential to greatly reduce some of the very risks currently most greatly affecting public health and the environment. Synthetic biology serves as one such emerging technology that, despite its potential benefits to various fields, gives policymakers pause until the human and environmental health risks posed by genetically engineered organisms are better characterized and assessed. Given various limitations of our current paradigm for making risk management decisions, some of which are caused by limitations of conventional methods of quantitative risk assessment (QRA), a modified approach to emerging technology characterization and assessment might be a needed step change. This paper demonstrates how one such approach - "solution-focused risk assessment" (Finkel, Hum Ecol Risk Assess 17(4):754-787, 2011)—can help evaluate synthetic biology products against conventional competitors. Specifically, this paper conducts a SFRA for Oxitec's engineered Aedes aegypti mosquito, which serves as a synthetic biology option for dengue virus vector control.
\end{abstract}

Keywords Synthetic biology $\cdot$ Comparative risk assessment $\cdot$ Governance

\section{Introduction}

Despite their potential promise, emerging technologies often pose various uncertain health risks that cause policymakers to hesitate to allow resultant products and processes to enter the market. Further complicating matters, there may be particular difficulty in quantitatively assessing risks associated with a technology or material's hazard, exposure, and effects, whereas such quantitative data serve as the crux of most regulatory approvals (Kuzma and Tanji 2010; Trump

Adam M. Finkel

afinkel@upenn.edu

1 University of Pennsylvania Law School, Philadelphia, USA

2 University of Michigan, School of Public Health, Ann Arbor, USA

3 Arizona State University School for the Future of Innovation in Society, Sandra Day O'Connor College of Law, Phoenix, USA

4 Arizona State University School for the Future of Innovation in Society, ASU Risk Innovation Lab, Phoenix, USA et al. 2017). Synthetic biology serves as one such emerging technology that, despite its potential benefits, including the potential to greatly reduce some of the very risks most greatly affecting public health and the environment, gives policymakers pause until the human and environmental health risks posed by genetically engineered organisms are better characterized and assessed (Carter et al. 2014). But our dominant paradigm for making risk management decisions may not be well suited to the needed comparative evaluation of emerging technologies (with their potential both for risk reduction and risk creation/exacerbation) against the current products and approaches now used to fulfill various human needs. Some of the deficiencies of risk management in turn stem from the limitations of conventional quantitative risk assessment (QRA) to evaluate significant uncertainties posed by synthetic biology and by current approaches. Therefore, a modified approach to emerging technology characterization and assessment might be a needed step change (Malloy et al. 2016a; Seager et al. 2017).

This paper builds from a report to the Alfred P. Sloan Foundation to apply a new science-policy paradigmreferred to in various of its related forms as "a decision 
framework that maximizes the utility of risk assessment," (NRC 2009), as "risk-based technology options analysis," or as "solution-focused risk assessment" (SFRA) (Finkel 2011) — to evaluate a proposed application of synthetic biology. Here, we explore the potential risks and benefitsthe probability, severity, and distribution of adverse consequences and desirable improvements in human welfare- that might follow the unrestrained release of genetically modified Aedes aegypti mosquitoes into the environment in an effort to promote vector control of dengue fever, a devastating tropical disease affecting hundreds of millions worldwide.

By emphasizing the SFRA paradigm, this article attempts to break new ground in relation to both risk assessment and risk management, and does so by going beyond the simple, often dichotomous ways decision-makers and the public think about both analysis and action (see discussion of this dichotomy, and the policy problems it produces, in PalmaOliveira et al. (2017)). The risk assessment questions that society generally poses about technologies and products often start and end with "is it safe?" Or, perhaps, they go a bit further to ask "do its benefits exceed its risks?" The risk management alternatives often start and end with "should we ban this activity, or ignore it?" We pose, and begin to answer, much richer questions here.

In order to pose more quantitative and detailed analytic questions, we view as central the use of modern methods of QRA that have been developed and refined over several decades in the exploration of chemical and radiological hazards (Kaplan and Garrick 1981; NRC 1983; Hassenzahl and Finkel 2008). QRA synthesizes information from basic sciences (e.g., toxicology, epidemiology, chemistry, statistics) to explore the probability that one or more adverse outcomes will occur from a product or process, and to gauge the severity of each outcome. The output of a useful QRA is not a yes/no pronouncement about the existence of a risk, a vague and subjective "threat level" such as a color-coded appraisal (Cox 2008), or even a fully numerical estimate of its likelihood and its consequence. It is, instead, a "characterization" of risk that offers information about (1) the extent of scientific uncertainty that, if analysts are honest and humble, precludes them from pinning down the probability or severity with precision; and (2) the extent and nature of interindividual variability in the risk, so that different populations can appreciate that probabilities and severities also depend on who is facing the hazardous condition(s) (Finkel and Gray 2018). Therefore, useful analytic questions and processes result in quantitative estimates of risk (not mere pronouncements of "safety" or the lack thereof), and in conclusions about the absolute acceptability of a product/technology, or about its relative merits compared to other products/technologies, that respect uncertainty (Risk Bites 2018).

These risk management questions also transcend the traditional governance options regulatory agencies generally turn to (Oye et al. 2014; Trump 2017). Typically, agencies evaluate a new or existing product, substance, or technology to determine whether it is too risky to allow, or to determine what level of risk reduction or risk-control methods would render it acceptably risky over time (see discussion on various synthetic biology cases in MacIntyre et al. 2017). The National Ambient Air Quality Standards for ozone and other pollutants set by the Environmental Protection Agency, Allowable Daily Intakes set by the Food and Drug Administration, and workplace exposure limits set by the Occupational Safety and Health Administration are all examples of risk-based decisions that treat hazards singly and allow incremental risks deemed reasonable.

In contrast, SFRA and similar decision paradigms start not by dissecting the "problem" of a particular risky product or technology, but by asking whether it offers a superior solution towards fulfilling one or more human needs than do alternative products/technologies addressing the same need(s). The arraying of alternative solutions can be narrow or expansive. For example, asking "how many parts per billion of bisphenol A (BPA) should be allowed to migrate from a plastic water bottle into drinking water?" is a typical first-generation risk management question; asking "which of these five materials, including BPA, should be permitted at a given concentration, and which should be banned or restricted?" is a solution-focused question; asking "how can governmental incentives, taxes, or investments in infrastructure reduce the runaway demand for tens of billions of plastic water bottles of any kind, with their effects on energy use, waste disposal, and other problems far beyond trace concentrations of endocrine disruptors?" is an expansive SFRA question.

As will become apparent in the final sections of this article, SFRA for an emerging-technology controversy such as this one is similar in many ways to "alternatives analysis" (Malloy et al. 2016b), but differs from it in at least two major ways. First, it estimates not only the risk of each alternative, but also its risk-reducing potential, so it could be described as "net-risk alternatives analysis." Secondly, SFRA does not necessarily look only at existing products in the market that fulfill a particular function (e.g., different solvents to dryclean clothes) to shed light on the safest or otherwise best alternative, but can go beyond searching for "the least risky way to perform function X" (e.g., put water in bottles) and ask "what is the least risky (or most net-risk-reducing) way to fulfill human need Y (e.g., provide clean water in the most convenient dispenser).

Applying the solution-focused paradigm to a synthetic biology application is both easier and harder than the above example suggests. It is easier in that the economic cost of controlling the risks of each competing solution is generally not an overriding concern. So rather than conducting 
what is essentially a comparative cost-benefit analysis (to find the solution that has the greatest excess of benefits over costs), this article deals in comparative risk analysis. It is harder, however, in that "risk" here is not just a function of the downside problems that each alternative product/ technology poses, but also a function of the upside benefit, construed as risk reduction, that each product promises (see also Bates et al. 2015). After all, the spectrum of methods to control dengue fever does not consist of consumer goods that satisfy economic wants, but ways to reduce the serious risk of an intractable disease. So, applying the SFRA method to these types of emerging technologies essentially becomes a "comparative net risk reduction analysis."

We emphasize that like any decision-making paradigm, SFRA must choose which alternatives to array with an eye both towards inclusiveness and simplicity. A coherent SFRA could look, for example, only at solutions that individuals can implement in their own lives, or exclusively at solutions that only state, federal, or even international governing bodies would have the resources and authority to implementor it could evaluate both kinds of intervention and perhaps suggest fortuitous combinations from each domain. In any case, although the act of comparing solutions is at the heart of this method, and although the comparison could be made impressionistically rather than quantitatively, and could depend largely on public (or special interest) preferences rather than more objective criteria, the kind of SFRA we advocate here places QRA at its core. In other words, SFRA is not just a mindset - a way to act on hazards rather than to continue to investigate them-but a method, a way to take specific action(s) based on careful quantitation, that reduces risks efficiently rather than merely setting aspirational targets for risk reductions.

This article applies a solution-focused approach to the topic of management and reduction in dengue fever transmission. Using SFRA, we compare the net risk profiles of various control options to attacking the dengue vector $(A$. aegypti) or the dengue virus itself. Specifically, we compare conventional options, emerging opportunities, and a specific synthetic biology advance-the engineered $A$. aegypti mosquito created by the company Oxitec-to demonstrate how a solution-focused approach can offer a robust avenue to evaluate risks of new technological options where limited quantitative information exists to populate a conventional risk assessment. We of course do not array all possible avenues to reduce dengue transmission here, but rather emphasize the conventional methods currently in widespread use, compared to several leading-edge methods including the Oxitec synthetic biology advance.

\section{Background: dengue fever and Oxitec}

Dengue fever is an infectious disease caused by the dengue virus. The dengue virus contributes to approximately 50 million infections, 500,000 hospitalizations, and 25,000 deaths annually (Guzman et al. 2010; Bhatt et al. 2013). The virus is commonly found in tropical and subtropical climates in Southeast Asia, Sub-Saharan Africa, and South America, and is endemic in more than 110 countries (Gubler 2010). Dengue has five major serotypes (DEN-1, DEN-2, DEN-3, DEN-4, DEN-5), which are transmitted to an uninfected host almost exclusively through the bite of an infected mosquito (Normile 2013). While infection of one strain of dengue will render its victim immune to that individual strain in the future, it will not promote long-term immunity to other strains of dengue, and could even contribute to more debilitating health outcomes if individuals are infected with multiple strains of the dengue virus throughout their lifetime (Endy et al. 2002).

The primary vector of dengue virus transmission is the Aedes aegypti mosquito. Aedes aegypti are also common vectors for yellow fever, chikungunya, and the Zika virus, particularly in tropical and subtropical regions. Infection with the dengue virus can occur in humans with a single bite of an infected mosquito (Canyon et al. 1999); notably, only female mosquitoes bite humans. Once infected with the dengue virus, the mosquito is infected and contagious for its entire lifespan of roughly 2-4 weeks duration. The first symptoms of dengue fever will arise approximately 4-7 days post-infection; while roughly $80 \%$ of those infected with dengue will be asymptomatic, about $15 \%$ will be afflicted by fever, headache, joint pain, and rash (Cobra et al. 1995). Rarer and more serious complications include the onset of dengue haemorrhagic fever, which may result in bleeding, shock, extensive pain along the limbs, and extremely low blood pressure in approximately $5 \%$ of cases (Clarke 2002). Severe disease (dengue haemorrhagic fever) manifests more often in babies and young children under 12 than in adults, and in contrast to many other infections, it is more common in children that are relatively well nourished (Ranjit and Kissoon 2011). The haemorrhagic variant of dengue has also been colloquially known as 'breakbone fever' due to the muscle and joint pain that has been described as though the infected victim were experiencing multiple bone-breaks and muscle injuries simultaneously (Ranjit and Kissoon 2011; Clarke 2002). For those who experience symptoms of dengue fever, mortality is estimated at $1-5 \%$ without treatment, and less than $1 \%$ with treatment. For those cases that require hospitalization, the $\mathrm{CDC}$ states that while no formal treatment exists for all cases, fluid replacement therapy can drastically improve health outcomes of patients (CDC). Across all cases, the economic cost of such illness has been 
estimated at approximately $\$ 61$ per family in Southeast Asia. This is greater than the monthly income for many families in low-income countries with high dengue susceptibility (Clark et al. 2005). Severe disease (haemorrhagic fever) carries a $26 \%$ mortality, and is additionally more dangerous for those with a high viral load, are immune compromised, or have a high body mass index (Ranjit and Kissoon 2011; Simmons et al. 2012).

Although governments and private organizations have been combatting dengue fever through an array of approaches for many decades, the disease continues to grow in incidence. The number of reported cases has increased by a factor of almost 2000-fold over the past 50 years (World Health Organization 2016). Even the nearly 1.7 million cases reported to WHO annually in the 2000-2008 period may be a severe underestimate; researchers estimated in 2013 that there may be between 67 and 136 million cases of dengue worldwide per year (Bhatt et al. 2013).

\section{Traditional approaches to mosquito population control}

Due to the lack of an effective vaccine (see below) and the role of Aedes aegypti as the main vector of transmission, two main strategies have been recommended by the WHO in order to reduce the incidence of dengue infection and the subsequent human and economic costs. These include (1) the deployment of physical barriers to reduce mosquito contact with humans, and (2) reducing the mosquito population within a given area through chemical means.

Physical mosquito barriers have been utilized throughout recorded history (Malaria Site, undated). Mosquito nets were improved circa 1980 by impregnating them with insecticides to kill mosquitoes that land on the netting. These nets are known as insecticide treated nets (ITNs), and are estimated to be roughly twice as effective as untreated mosquito nets at preventing disease (Hull 2006; Bachou et al. 2006). Modern ITNs, which are treated with insecticides such as permethrin or deltamethrin, are distributed for approximately $\$ 2.50-\$ 3.50$ per net by the United Nations and WHO (VOA, undated). However, ITNs are recommended to be re-treated approximately every 6 months in order to ensure their continued effectiveness, increasing the cost burden for rural and poor families. As this chemical coating wears off, the risk of bites and subsequent infection by mosquitoes increases as they are not killed at the net barrier (Yakob and Guiyun 2009). More importantly, while bed nets are potentially useful for malaria control, the A. aegypti mosquitoes that transmit dengue fly and bite during daylight hours; hence, a recent UK House of Lords scientific report concluded that "Insecticide treated mosquito bed nets, which can prevent malaria transmission, are therefore not effective against dengue" (House of Lords 2015).

A complementary approach that has been adopted by certain governments has been the cleaning up of potential mosquito breeding areas. Known as source control, national governments such as Singapore take up a shared effort with local communities to educate their citizens on the need to clean up dark and damp areas, objects such as discarded tires that collect stagnant water, draining swampy areas, and removing other potential drivers of mosquito breeding (Ooi et al. 2006). While helpful, source control requires significant and repeated manual labor to be effective. However, it is possible that source control could be made more effective than at present if local or national governments became willing to levy fines on individuals and companies who are responsible for maintaining sources of stagnant water on their properties.

In comparison to the use of physical barriers, which are most often used in individual households, chemical and biological mosquito population control methods are designed to combat mosquito populations over a larger geographic area. Of these methods, chemical spraying of insecticides is the most common. One of the most effective and widespread chemicals used to combat mosquitoes for human health reasons is dichlorodiphenyltrichloroethane (DDT), first used as an insecticide in 1939 (Müller 1995). Although DDT was banned via global moratorium in 2001 via the Stockholm Convention on Persistent Organic Pollutants, it is still used in parts of the developing world to kill disease-carrying mosquitoes. Similarly, other chemical sprays have been introduced after calls for a global moratorium on DDT use (i.e., lindane, malathion, and propoxur; of these, lindane is possibly carcinogenic, and all have relatively low reference doses). For a very recent example of the ecological harm pesticides can cause, see Guarino (2016) for a discussion of how aerial spraying with the organophosphate insecticide Naled (dimethyl 1,2-dibromo-2,2-dichloroethylphosphate) apparently and unintentionally killed millions of honeybees in South Carolina (Guarino 2016).

As an alternative to area spraying, mosquito traps are often used for more targeted population control. These are small containers with a reservoir of insecticide, designed to attract nearby adult mosquitoes. Known as lethal ovitraps, they are built to be attractive nesting sites for mosquitoes to deposit their eggs in (Reiter et al. 1995). The primary benefit of ovitraps is the absence of area chemical spraying, meaning a less invasive or environmentally hazardous approach to mosquito population control. However, this method is not widely used in much of the developing world due to its expense and limited spatial range in comparison to chemical aerosols.

Similarly, oil drips use chemical means to help limit opportunities for mosquito population growth. This method 
is simple: the oil drip smothers mosquito eggs, cutting off their oxygen supply, while simultaneously preventing other mosquitoes from laying further eggs in that area (Le Prince 1915). However, this method is generally used retroactively, and must be applied in all areas of stagnant water which mosquitoes favor for laying their eggs.

These traditional methods of mosquito population control have often been used in tandem, particularly in large projects within areas of high disease prevalence and heavy mosquito populations. However (Weill et al. 2003), instances where recurring insecticide use has contributed to partial or full resistance to the chemical agent in a given geographic area has dampened enthusiasm for chemical controls (Ranson et al. 2001; Brown 1986). Given the limitations of chemical and physical options to control the spread of mosquito populations, organizations such as the US Environmental Protection Agency (EPA) have called for the development and use of alternatives to insecticides that have lower environmental and human health risks. Likewise, the UK Parliamentary Office of Science and Technology noted the importance for innovation of affordable, effective, and less risky insecticide alternatives in many developing countries with endemic diseases such as dengue, Zika, malaria, and others (EPA; Institute of Physics 2010).

\section{Newer approaches to mosquito control}

Given concerns about the efficacy and safety of traditional controls, various methods in development tend not to focus on physical barrier approaches, but rather emphasize mosquito population control and general vector reduction, reducing the need for proper use and upkeep of nets and other materials on a household-by-household basis. These methods range from vaccine development, to biological population suppression, to the introduction of less familiar predators or parasites in the mosquitoes' local environment.

\subsection{Efforts towards a dengue vaccine}

There is currently no cure for dengue fever, nor a vaccine that is fully effective against all serotypes (Whitehorn and Farrar 2010). This is primarily due to the limited protection offered by past vaccine products (or the low percentage efficacy enjoyed by those given the prototypical vaccine in resisting the disease versus the unvaccinated) and an inability to inoculate against all serotypes of dengue (Webster et al. 2009). The development of a successful dengue vaccine is made more difficult by the fact that measurable signs of immunity within humans, such as dengue antibodies, do not currently arise within dengue vaccine recipients. Many vaccine candidates have exhibited insufficient or low levels of immunity among those given the vaccine. Specifically, despite the growing pipeline of dengue vaccine candidates "including live attenuated, inactivated, chimeric, DNA, and viral-vector vaccines, some of which are at the stage of clinical testing," existing vaccine candidates have generally expressed suboptimal efficacy (i.e., low rates of immunity in those given the vaccine) or are cost-ineffective for widescale immunization (Webster et al. 2009). Various national governments and pharmaceutical companies, including the US National Institutes of Health, Sanofi Pasteur, Inviragen, Butantan Institute, Takeda, Merck, and GSK, have been actively engaged in research to develop a more effective vaccine (Coller and Clements 2011).

One vaccine candidate which fosters incomplete immunity (Dengvaxia) was commercialized in 11 countries in 2016 by Sanofi Pasteur. Preliminary results from Phase III trials noted a $56 \%$ reduction in incident dengue cases in 10,275 children within Indonesia, Malaysia, the Philippines, Thailand, and Vietnam (Guy et al. 2011). By September 2014, the company's dengue vaccine candidate completed its second and final Phase III clinical trial in Latin America, where Phase III trials collectively utilized 31,000 volunteers. In the study, researchers made use of randomized, observerblind, placebo-controlled multi-center trials where test subjects were randomized to either receive three injections of the dengue vaccine or a placebo ( 2 to 1 ratio) at 0,6 , and 12 months (Genetic Engineering and Biotechnology News 2014). At the end of the trial, the company noted their vaccine candidate as having efficacy for the four most prevalent serotypes, although to differing degrees (information below in Table 1). These initial findings indicate that while the vaccine candidate expresses strong potential to reduce dengue incidence in vulnerable populations, it does not fully promote herd immunity, or prevent the disease in many, particularly those living in areas endemic with serotypes ST1 and ST2.

However, in 2017 support for Sanofi's vaccine was challenged by concerns of potential side effects raised by various Philippine non-governmental organizations, leading to a statement by the World Health Organization that the vaccine candidate should not be administered to patients who have not previously had a specific serotype of dengue fever (Grady and Thomas 2017). Sanofi acknowledged (CNN Philippines Staff 2018) that about 10 percent of 800,000 children given the vaccine in the Philippines now face a risk of experiencing a particularly severe bout of dengue fever,

Table 1 Sanofi Pasteur phase III clinical trial serotype efficacy in resisting dengue infection

\begin{tabular}{ll}
\hline Dengue serotype & Efficacy $\%$ \\
\hline ST1 & 50.3 \\
ST2 & 42.3 \\
ST3 & 74.0 \\
ST4 & 77.7 \\
\hline
\end{tabular}


because the vaccine may prime seronegative recipients to experience a secondary infection upon their first exposure to the live dengue virus. In December 2017, the Food and Drug Administration in the Philippines suspended the sale and distribution of Dengvaxia in that country. Researchers now recommend that the vaccine should only be given to seropositive individuals, which would complicate its administration and lead to a program that does not protect individuals against their first infection (Aguiar et al. 2017).

\subsection{Novel mosquito predators and diseases}

The introduction of mosquito predators provides an alternative control pathway. The Gambusia affinis or mosquitofish feeds on mosquito eggs, and other species of carp, minnow, and tilapia consume mosquito larvae (Stearns and Sage 1980; Krumholz 1948). However, the direct introduction of tilapia and mosquitofish has generated some adverse consequences for biodiversity (particularly for smaller fish and aquatic life in areas where the invasive species is introduced), and may not be a suitable control method in many environments (Stearns and Sage 1980). Such invasive species such as various breeds of tilapia can both directly compete for other sources of food with native species and/or prey on native species, which could disrupt biodiversity within a particular area (Zambrano et al. 2006).

Aside from animal predators, various species of mosquitoes are susceptible to disease and infection by several viruses, bacteria, protozoa, and fungi (Cole and Hoch 1991). A notable experiment in this regard includes mosquito infection via the Wolbachia bacteria to reduce mosquitoes' ability to transmit infectious diseases (Moreira et al. 2009). Wolbachia prevents mosquitos from carrying infectious viruses such as Zika in their saliva, thus potentially providing an approach to infection management (Dutra et al. 2016). The bacteria is also being developed as a pesticide that prevents infected mosquito offspring from surviving. In early 2016, the US EPA began reviewing an application from the US biotechnology company "MosquitoMate" to use Wolbachia as a population control method in tiger mosquitoes - the same company is looking to extend the use of this bacteria in Aedes mosquitoes (Waltz 2016). However, some of the same risk scenarios posited below about the Oxitec application also apply to the use of Wolbachia: if released into $A$. aegypti, it may jump in the environment into other insects, with unknown ecological consequences. And, unlike the Oxitec application, mosquitoes infected with Wolbachia have no fitness deficits, and in principle may thus introduce an irreversible change into the environment (Silva Loreto and Wallau 2016; Gentzel 2016).

\subsection{Improvements to irradiation of released mosquitoes}

A number of government agencies around the world, including the US, Mexico, and Guatemala, have implemented population suppression measures on various species of mosquitoes by hatching and irradiating non-biting males (Klassen 2009). In this approach to disease control, male mosquitoes are irradiated in order to sterilize them, removing their ability to procreate (Dame et al. 2009). The large numbers of sterile male mosquitoes reduces the reproduction rate in the field, and as a result suppresses the mosquito population.

However, irradiation has various drawbacks; in particular, male mosquitoes can be significantly weakened during their sterilization and have difficulty competing for mates against healthy and virile partners, which can ultimately limit the method's effectiveness (WHO). Given the obvious limitations, research continues on developing more effective approaches at mosquito population control through sterilization (Fu et al. 2010).

\section{Overall observations about conventional approaches}

Collectively, various approaches have been developed in recent years as a means of mosquito population control that could offer improvements over existing technologies or paradigms. Each approach to mosquito control has its own set of challenges (see Table 2). They include, for example, the need for constant vigilance in the growth and production of mosquitoes, the threat of mosquito migration beyond controlled areas, and cost concerns of acquiring and monitoring such mosquitoes in developing countries. With respect to vigilance and accuracy in the mosquito growth processes, mistakes and deviations from the standard operating procedures for the mass rearing and irradiation of mosquitoes and other insects may result in the release of non-sterilized mosquitoes before the problem is identified and quelled (FAO 2003).

An additional concern includes the migration of mosquitoes from other areas into the treated area, requiring any alteration to controlled mosquitoes to be robust and longlasting. Alphey et al. (2010) describe sterilization and modification efforts of mosquitoes as cost-, management-, and operations-intensive. It is therefore presumed that developing countries are often unable to take advantage of these technologies due to limitations of public health infrastructure and governance to effectively deliver mosquito control services to the public individually or across wide regions on behalf of the government. 


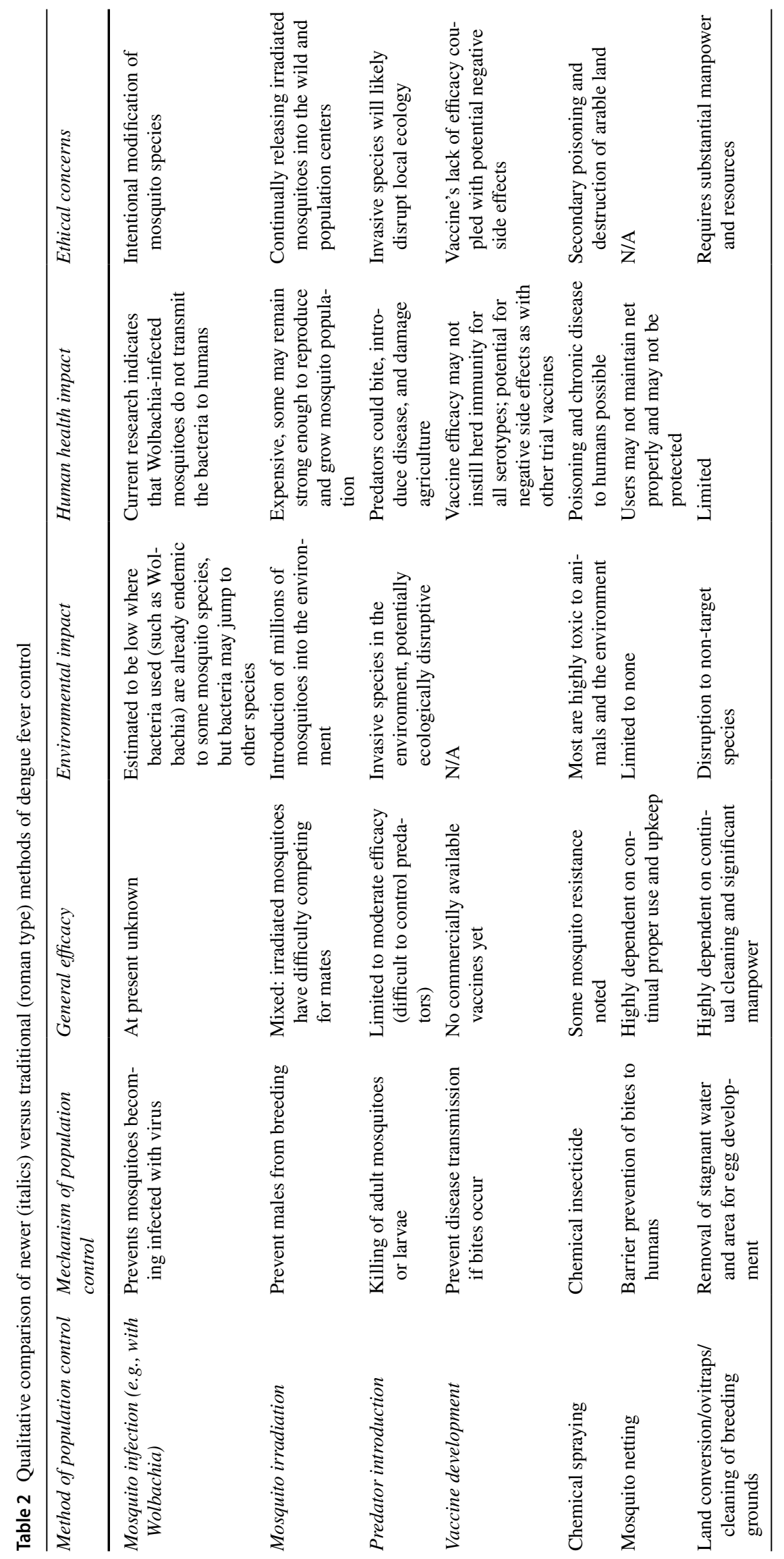




\section{Role of synthetic biology as a possible breakthrough approach to dengue control}

After many decades of trying to stem the incidence of dengue infection, a synthetic biology innovation may offer a new and promising approach to address this age-old public health problem. Oxford Insect Technologies ("Oxitec"), a United Kingdom (UK) company, is one of the leading organizations focused on the development of novel approaches to reducing the incidence of dengue fever. [Note: although Intrexon Corporation acquired Oxitec Ltd. in late 2015, throughout this case study we refer to the synthetic biology mosquitoes as the "Oxitec application."] Utilizing advanced genetic manipulation techniques, Oxitec has developed genetically altered mosquitoes whose offspring are unable to live past the larval stage, and hence cannot procreate or bite humans (Harris et al. 2011; Wise de Valdez et al. 2011). Specifically, Oxitec has constructed a genetically modified male mosquito that, without access to tetracycline, will live in the wild only long enough to mate. These mosquitoes pass on to all their progeny (both males and females) the same lethal mutation they were given; these offspring die within a few days.

Although this paper does not explicitly address the rising challenge of Zika, our conclusions are also relevant to this infectious disease. Like dengue, the Zika virus is also carried by the Aedes aegypti mosquito, and is beginning to spread into the US. For most people, Zika does not present the same level of health risk as dengue. However, growing research on its association with fetal development - and developmental conditions such as microcephaly-as well as neurological conditions such as Guillain-Barre Syndrome, makes managing Zika a particularly complex risk challenge. Using genetically modified mosquitoes to control dengue will also have a direct impact on the spread of Zika-and because of this, Oxitec is renewing efforts to introduce their mosquitoes in Zika-infected areas (Oxitec, undated). It is likely that the additional control of Zika in dengue-infected areas will further support our conclusions that-subject to the many provisos given below-the use of genetically modified Aedes aegypti appears to be a promising method for consideration in reducing mosquito-borne infectious disease (Pollack 2016; Dutra et al. 2016).

\subsection{Oxitec's OX513A tetracycline-dependent engineered mosquito}

According to Oxitec, the primary benefit of their innovation is a rapid decline in the local Aedes aegypti population in a given area without the use of insecticides or the substantial human resources associated with source reduction approaches. Using synthetic biology, Oxitec engineered a strain of male Aedes aegypti (known formally as OX513A) such that its offspring would not survive to reproduce without access to the antibiotic tetracycline. Tetracycline is a synthetic antibiotic, and not naturally available (although it can be found in trace quantities in the environment), thus leading to a synthetic chemical dependency in the emerging mosquito population (Daghrir and Drogui 2013). This enables the mosquitoes to be bred in captivity. When released, the synthetic biology mosquitoes mate with wild females. However, without access to tetracycline, their progeny are not able to reproduce. Oxitec specifically describes this process as follows:

"Without tetracycline, tTAV protein is produced, which simultaneously binds to transcriptional machinery and tetO sites thereby enhancing the expression of the self-limiting gene. This positive feedback system produces large amounts of tTAV which binds to more and more transcriptional machinery [...]. The inhibition of essential gene expression leads to cell death and the death of the insect before it reaches adulthood" (Oxitec).

Oxitec conducted its first study of their mosquitoes in a multi-wave release in the Cayman Islands from 2009 to 2011 (Harris et al. 2012). Beginning with a preliminary release of nineteen thousand mosquitoes in 2009, Oxitec later engaged in a large-scale release of over three million male mosquitoes in 2010. These mosquitoes were released at designated "mosquito points" every $90 \mathrm{~m}$ over a 16-hectare area over a 23-week period between May and October, 2010. At the end of the trial, Oxitec noted that $88 \%$ of all mosquito eggs found in Grand Cayman were the offspring of genetically modified Oxitec mosquitoes, and the overall Aedes aegypti population in Grand Cayman had declined by $80 \%$ over a three-month period (Harris et al. 2012). Oxitec expanded their environmental trials to Malaysia (2010) and Brazil (2011).

A number of commentators have suggested benefits of this novel approach. With regard to potential economic benefits in the Florida Keys, writer and environmental reporter Kiera Butler stated that Aedes aegypti eradication in Key West, Florida would cost approximately $\$ 200,000-\$ 400,000$ each year using Oxitec's eggs (Butler 2012). This is roughly half of what Key West currently pays for insecticides, or approximately $\$ 800,000$ (Butler 2012). According to former Oxitec CEO Hadyn Parry, a less expensive alternative for mosquito population control was a primary driver for Oxitec's investment in the approach (Butler 2012).

Oxitec's scientists have also described the potential environmental benefits associated with their alternative for mosquito reduction. Specifically, the use of this mosquito population control technology was noted as reducing the use of aerial or land-based insecticide spraying (Wise de Valdez et al. 2011; Harris et al. 2011). In a related context 
on bullworm reduction, the US Department of Agriculture (USDA) claimed that the a biological insecticide option is "the environmentally preferred alternative" to mosquito population control due to a lack of reliance on potentially toxic and poisonous chemicals (USDA 2008).

Despite the potential benefits of the approach, scientific concerns with Oxitec's mosquito control method and subsequent release have been raised. Observers including Alfred Handler of the Gainesville (Florida) Agriculture Department have questioned the success of the results and the potential for these synthetic biology mosquitoes to evolve beyond their lethal genetic modification (Pollack 2011). Additionally, Todd Shelly from the Agricultural Department of Hawaii suggested that $3.5 \%$ of Oxitec's synthetic biology mosquitoes were able to survive to adulthood without tetracycline, leaving the potential for the propagation of new genetic material into the wild that could trigger immunity to the TTAV condition and result in future mosquito population growth (Pollack 2011).

Other commentators have raised process and ethical concerns. For example, Genewatch UK and Gainesville's Agriculture Department were alarmed by the lack of public notice given prior to Oxitec's mosquito releases. Along with concerns regarding lack of public notice, additional concerns arose regarding the ethical and potential health implications associated with the release of a "new" insect into the environment (Ostera and Gostin 2011). GeneWatch UK Director Helen Wallace argues that Oxitec has potentially exaggerated the benefits of genetically modified Aedes aegypti to nations susceptible to the disease (Mendes 2012). Wallace contends that concerns related to "the potential adverse effects of this technology" such as the potential health consequences associated with large-scale tampering and elimination of Aedes aegypti in the ecosystem are still not fully understood, and that these concerns were not resolved prior to the release of millions of such mosquitoes into Grand Cayman, Malaysia, Panama, and Brazil (Wallace 2013).

Despite these concerns, in January 2014, the government of Panama agreed to the controlled release of Oxitec's mosquitoes near Panama City (PR Newswire 2014). Oxitec planned to release approximately 240,000 genetically modified mosquitoes per week for several months (Natural News). This announcement was met with concern among some stakeholders, with GeneWatch UK claiming that such a release lacks any formal risk assessment by Oxitec, which is a requirement under EU law as according to Regulation (EC) No 1946/2003 Articles 4 and 5 (GM Watch 2014). Wallace argued that such risk assessment is essential "so local people can be sure they know the pros and cons [related to the technology]" and that "it is negligent of Oxitec to fail to do this risk assessment, which should meet European standards" (GM Watch 2014).

\section{Synthesis and appraisal}

A comparative evaluation of the traditional, newer, and synthetic biology approaches to controlling dengue fever, one informed by a "solution-focused" orientation to risk management, and by the consistent treatment of uncertainty in the risks of all alternatives, suggests that the Oxitec synthetic biology application may offer incremental benefits significant enough to justify its incremental risks. We emphasize that insufficient information exists on the probabilities and severities of the various downside-risk scenarios for us to make this conclusion in absolute, stand-alone terms; that is, whether Oxitec's approach would reduce risks, increase them, or provide new risks and risk reductions in roughly equal measure. However, the same ambiguity surrounds most of the conventional approaches to controlling dengue, so that a pronouncement that a given approach is risk-reducing (or not terribly risk-increasing) is misleading without comparing it to other approaches that may offer more net risk reduction (or less net risk increase). So for the reasons discussed below, we suggest that this synthetic biology application may hold up well in such a comparison-which is not necessarily the case for other synthetic biology applications (Finkel 2018).

Our primary enthusiasm for this application begins with an appraisal of the parade of largely ineffective and potentially risky control measures in practice during a period of time in which the number of dengue cases reported to the WHO has increased by thirtyfold. As Paul Reiter, a professor of medical entomology at the Pasteur Institute, stated in a 2012 New Yorker article, "Dengue is a terrible disease, just terrible... Its danger is impossible to exaggerate. And none of the methods used right now for dengue control are working. None" (Specter 2012). Equally important, of course, we have considered the list of known and speculative risks (both substantive and risks to public legitimacy) of the Oxitec method, and conclude that its potential as a positive game-changer against dengue and other viral diseases (notably the Zika virus) mitigates at least to some degree in favor of its carefully monitored introduction into more areas where A. aegypti is endemic-especially if the developers can succeed in making one or more modifications that might decrease the downside potential.

Although performing any quantitative risk assessment de novo is beyond the scope of this paper, we have applied a "solution-focused" governance paradigm to the spectrum of approaches to control dengue, synthesizing existing information on

1. the probabilities that each approach can succeed in reducing the burden of disease; 
2. the magnitude of the benefits associated with such success;

3. the probabilities of each downside scenario that increases risk; and

4. the severity of each such outcome.

Conceptually, the most attractive approach(es) to control dengue fever is the one whose expected risk-reduction benefits, over and above the benefits of competing approaches, most exceed its probability-weighted array of harms (again, harms incremental to those of competing approaches).

We first offer several general observations about the various risk-risk comparisons in this case study. More so than in some other cases involving new risks from synthetic biology, various grave scenarios offered in opposition to the Oxitec approach are highly speculative, vague, and conflate possibility with probability. In other words, merely because a worrisome scenario can happen does not necessarily mean that the probability-times-consequence of the harm is significant or is more significant than the harm of an alternative course of action. An observation epitomizing this inchoate opposition comes from the U.K. environmental group GeneWatch, whose director told The New Yorker that "to open a box and let these man-made creatures fly free is a risk with dangers we haven't even begun to contemplate" (Specter 2012). This type of statement pushes several hot buttons, notably the allusion to Pandora's Box and the prospect of tinkering with creation itself, but makes no attempt to identify any particular danger or contemplate its probability or severity, and gives no credit to those who, however imperfectly, have tried to array the hazards, estimate the probabilities, and describe the potential harms.

Both formal risk assessments and public opinion have contributed some scenarios opposing the Oxitec method that perhaps should be flagged as fanciful-not inconceivable, but qualitatively different from scenarios that have some basis in evidence and some prospect for estimation of their risks. For example, the United Nations Development Program risk workshop in 2008 discussed 31 downside scenarios and ranked as one of the six most worrisome scenarios one in which wild female mosquitoes become more aggressive as a result of mating with modified males containing the dominant lethal gene, leading to more biting of humans - but the risk assessment offers no explanation for how this could occur, and even notes that laboratory studies of this eventuality have been carried out and saw no effects on female behavior (Beech et al. 2009).

More recently, a rush to blame synthetic biology mosquitoes was evident when the first cluster of Brazilian microcephaly cases was identified in conjunction with the Zika virus, and concern was expressed that the outbreak was caused by the Oxitec mosquitoes (Reynolds 2016). Indeed, in a 2016 survey conducted by the Annenberg Public Policy
Center at the University of Pennsylvania (Harvey 2016), while fewer than half of the 1014 respondents could identify Brazil as the focal point of the recent cluster, 35\% believed that it was caused by the release of synthetic biology mosquitoes elsewhere in Brazil by Oxitec (Harvey 2016; Wilcox 2016). It is ironic, we note, that less attention internationally was paid to the possibility that a large Brazilian government program in 2014, using a conventional mosquito control intervention - the addition of the larvicide pyriproxyfen to water supplies - might have contributed to the microcephaly cluster (Navarro 2016).

One curious aspect of many of the concerns raised about the Oxitec application is the failure to distinguish between "risk" in the sense of incremental harm versus "risk" in the sense of "failure to succeed." Entrepreneurs themselves sometimes emphasize "enterprise risk" (financial or other harm to their endeavor) over public risk, but here it is analysts and critics who are putting "failure to succeed" into a list that primarily includes health, environmental, and other harms (Paoli and Wiles 2015). For example, the otherwise excellent and pathbreaking Commonwealth Scientific and Industrial Research Organisation (CSIRO) risk assessment lists as one of the five major risk endpoints the possibility that the progeny mosquitoes will not die soon after birth. Although this would be disappointing, it would increase the overall mosquito population from $\mathrm{N}$ to $[\mathrm{N}+\mathrm{n}]$, where the $n$ modified organisms released into the environment are a tiny fraction of the prior population-at least for first-generation progeny (Hayes et al. 2015). This is a particular virtue of the Oxitec innovation; by creating a hybrid mosquito that is fit enough to compete with wild-type males but otherwise having no fitness advantages over its wild-type comparator, it ensures that "failure to succeed" will leave the dengue problem no worse than it would be had the attempt not been made.

In addition, when the debate about Oxitec has become polarized, we often see a very fundamental clash of worldviews emerge, focused on the inherent place of the mosquito in nature. On one hand, some advocates fall back to the notion that we humans cannot divine the role of this organism as it has integrated itself into ecosystems over millions of years; hence, eliminating it from an area could have devastating and unpredictable consequences. Others, on the other hand, however, make more pragmatic, perhaps cavalier, arguments: "if there was a benefit to having them [mosquitoes] around, we would have found a way to exploit them" (Fang 2010). In the same article, a mosquito control officer in Florida (Joe Conlon) offered that "If we eradicated them tomorrow, the ecosystems where they are active will hiccup and then get on with life. Something better or worse would take over." So in the clash over Oxitec, we see highly risk-averse positions juxtaposed with highly optimistic, "creative destruction" orientations. 
In this final section of this paper, we summarize the case study and our rationale for our tentative conclusion about the Oxitec innovation, in this logical order of discussion:

1. An appraisal of the efficacy of each of the currently available methods of control, which will reinforce the need for a step change in our ability to combat the disease;

2. An appraisal of the risks of the current methods;

3. Efficacy of the Oxitec approach;

4. A structured discussion of the risks of the Oxitec application, in which we introduce each potential risk, explain ways in which that risk scenario might be exaggerated, and suggest ways for Oxitec to further allay concerns about each scenario by improving their production process;

5. A brief summary of the need for better management and communication (by Oxitec and by host governments) of the public process surrounding development and deployment of the technology; and

6. Synthesis and a recommendation for a portfolio approach, in which the synthetic biology application could become a first line of defense, bolstered by (improved) use of several of the extant alternatives.

\subsection{Status quo efficacy}

The two kinds of problems most in need of innovative remedies are those where "nothing has been tried" and those where "everything we've tried isn't doing the job." The scourge of dengue fever (and the growing concern about the Zika virus) carried by $A$. aegypti is clearly in the latter category. For many decades, public health agencies around the world have brought to bear a portfolio of physical, chemical, biological, and medicinal weapons against the disease and/or its mosquito vectors, during which time the incidence of dengue has steadily risen and its range has steadily increased. Based on some first principles, the continuing saga of increased effort for decreased results may not be at all surprising, given that:

- Physical barriers and environmental cleanups are laborintensive to deploy and maintain, and, in the case of bed netting, may be somewhat futile "keys under the lamppost" strategies, given that A. aegypti mosquitoes tend to bite during daylight hours;

- Chemical countermeasures are only effective within the "therapeutic dose window," where the dosage is concentrated enough to adversely affect the target species, but not so concentrated as to overwhelm the ecosystem, and they are only effective so long as the target species has not evolved resistance;

- First-generation biotechnologies, particularly the release of irradiated male mosquitoes, similarly fail to navigate within a narrow "therapeutic window," in the sense that the mutant organisms need to be fit enough to compete with wild-type males, but not so fit that their very presence in the ecosystem poses a threat; and - The efficacy of any vaccine is compromised by the fact that there are at least five serotypes and nearly 50 strains of the dengue virus, and by the downside risk of causing disease in seronegative individuals, particularly children (Aguiar 2018).

Surrounding most of these interventions is the difficulty of mobilizing and maintaining what amount to "brute force" initiatives, ones that depend on cooperation and effort by the citizenry. The gap between theoretical efficacy and practical efficacy was never better expressed than by pioneering tropical disease worker Dr. Fred Soper, who apparently said in the 1940s that "if you have a democracy you can't have [mosquito] eradication" (Gladwell 2001). In other words, the conventional approaches do not fare well in an efficacy-for-the-risk appraisal, but fare even less well when one considers the non-risk compromises they impose on the citizenry.

\subsection{Status quo risks}

The most salient aspect of the risks of conventional methods is that most of them are quite familiar and accepted as the health and environmental "cost of doing business." In this regard, they are rather like the known harms of burning coal for electricity generation-the harms accrue inexorably, and we often have to be reminded of their scale, as in the more than 10,000 premature deaths in the U.S. annually attributable to particulate matter in the ambient air from coal-fired power plants (Clean Air Task Force 2010). The acute poisonings and the increase in cases of chronic disease attributable to insecticides used against mosquitoes, and the effects on agricultural productivity documented where novel predators have been introduced and where pesticides have been over-applied, are the "new normal" resulting from conventional mosquito control (Rowe 2014; Follett and Duan 2012). The coal/nuclear analogy is also in part apt because many of the risks of conventional mosquito control accrue to workers, who bear the brunt of chemical exposures and the injury risks that accompany strenuous physical labor.

This is not to say that all these "conventional" risks are well acknowledged. For example, researchers have found that it is often the second exposure to one of the related dengue viruses that causes serious illness or death. For that 
reason, vaccination programs may bring offsetting risks with them; as virologist Janet Smith has put it, "We don't want to prime people for severe dengue disease by delivering their first exposure to the virus in the form of a vaccine" (Williams 2014). And as with many other risk-risk tradeoffs in public health, the workers who administer the conventional controls (in this case, those who apply pesticides, remove standing water from populated areas, or apply oily films to stagnant water) often bear disproportionate risks from the remedies they deliver.

To oversimplify, the risks of conventional controls and the risks of the Oxitec alternative differ in kind: the former may well have the larger expected value, but a shorter righthand tail, whereas the latter may well be smaller "on average" but carry a longer and more ominous right-hand tail of lower-probability, higher-consequence problems. Mathematically, it is quite common for the uncertainty distribution for one quantity to have a smaller expected value but a larger upper bound than that of another quantity. Consider a risk A whose uncertainty is lognormally distributed with a median value of 1000 and a logarithmic standard deviation of 1 . The uncertainty in a different risk B is also lognormal, with a median of 200 and a logarithmic standard deviation of 2. Not only does risk A have a typical (median) value that is 5 times that of risk B (1000 versus 200), but A's expected value (about 1650) is larger than that of B (about 1480). But the 99th percentile value for $B(20,960)$ is more than twice as large as that of $A(10,240)$. This analogy is imperfect and quite possibly unfair to one set of controls or the other, but the same kind of expectation/variance tradeoff has been with us for many decades in the form of the choice between coal and nuclear sources of electricity generation (Lave and Freeburg 1973). By and large, we in the US have come to live with the inexorable damage from coal, measured in terms of respiratory mortality, occupational injury and illness, and $\mathrm{CO}_{2}$ emissions, rather than to embrace a competing energy source with far lower "goes with the territory" harms but greater potential harms should disaster strike at the source or at the sites of waste disposal.

\subsection{Synthetic biology efficacy}

At this writing, we only have two data points about the possible efficacy of the Oxitec solution. The first is the observation that between April and October 2014, approximately 70 separate releases of Oxitec mosquitoes in a residential suburb of Arraijan, in western Panama, led to an 93\% reduction in the number of $A$. aegypti insects in the area (Gorman et al. 2016). More recently, between April and December 2015, releases of the Oxitec mosquito in the south-eastern Brazilian city of Piracicaba led to an $82 \%$ reduction in the number of wild-type larvae in that area (Pollack 2016). Obviously, more ground-level work would have to be done to determine whether these reductions could be increased with longer-lasting releases and/or releases over a broader geographic area.

Depending on one's point of view, it is either a "feature" or a "bug" that by definition, populations of mutant mosquitoes must be released repeatedly every several weeks so that the remaining wild-type organisms do not mate and restore the original population. This adds to the cost of the intervention, but also allows for policy changes that would reverse the intervention and return the ecosystem to the status quo ante.

However, construing "efficacy" as a reduction in vector numbers may be misleading. What is really needed is research into any reduction in dengue or other disease incidence associated with the intervention.

\subsection{Synthetic biology risks}

In Table 3, we offer a structured way to consider 11 of the most salient risk scenarios for the Oxitec application that may merit QRA and subsequent quantitative risk-risk comparisons against the risks of conventional methods to control A. aegypti mosquitoes. Although the table does not discuss all the plausible risk pathways, it does include all of the scenarios deemed most worrisome in the two most useful risk appraisals conducted to date (see below), along with selected others we found illustrative.

In keeping with the main theme of this paper-that synthetic biology risks may be acceptable if they are accompanied by substantial benefits and if they compare favorably to the risks of current applications to meet the same human need-for each synthetic biology risk pathway the table provides two additional pieces of context: (1) a brief mention of whether and why the risk might be less probable and/ or less severe than worst-case thinking would dictate; and (2) preliminary thoughts about how developers of the synthetic biology application might strive to reduce either the probability or the severity of this risk further by additional innovative work.

Although all attempts to appraise risks exist along a continuum of analytic sophistication, one bright line can be drawn to demarcate "serious" appraisals from others: the former must at least attempt to gauge whether an outcome is certain, likely, probable, possible, remote, or impossible, and to gauge whether the consequences assuming the outcome occurs would be apocalyptic, severe, troubling, mild, or trivial (Finkel 2018). Unfortunately, much of the informal and formal commentary about the Oxitec application has consisted of "risk-like" pronouncements-assertions that something with specific import can happen, but with no mention of likelihood, or that something can happen with some probability but with no mention of its consequencesrather than serious risk assessment. For example, the 2016 


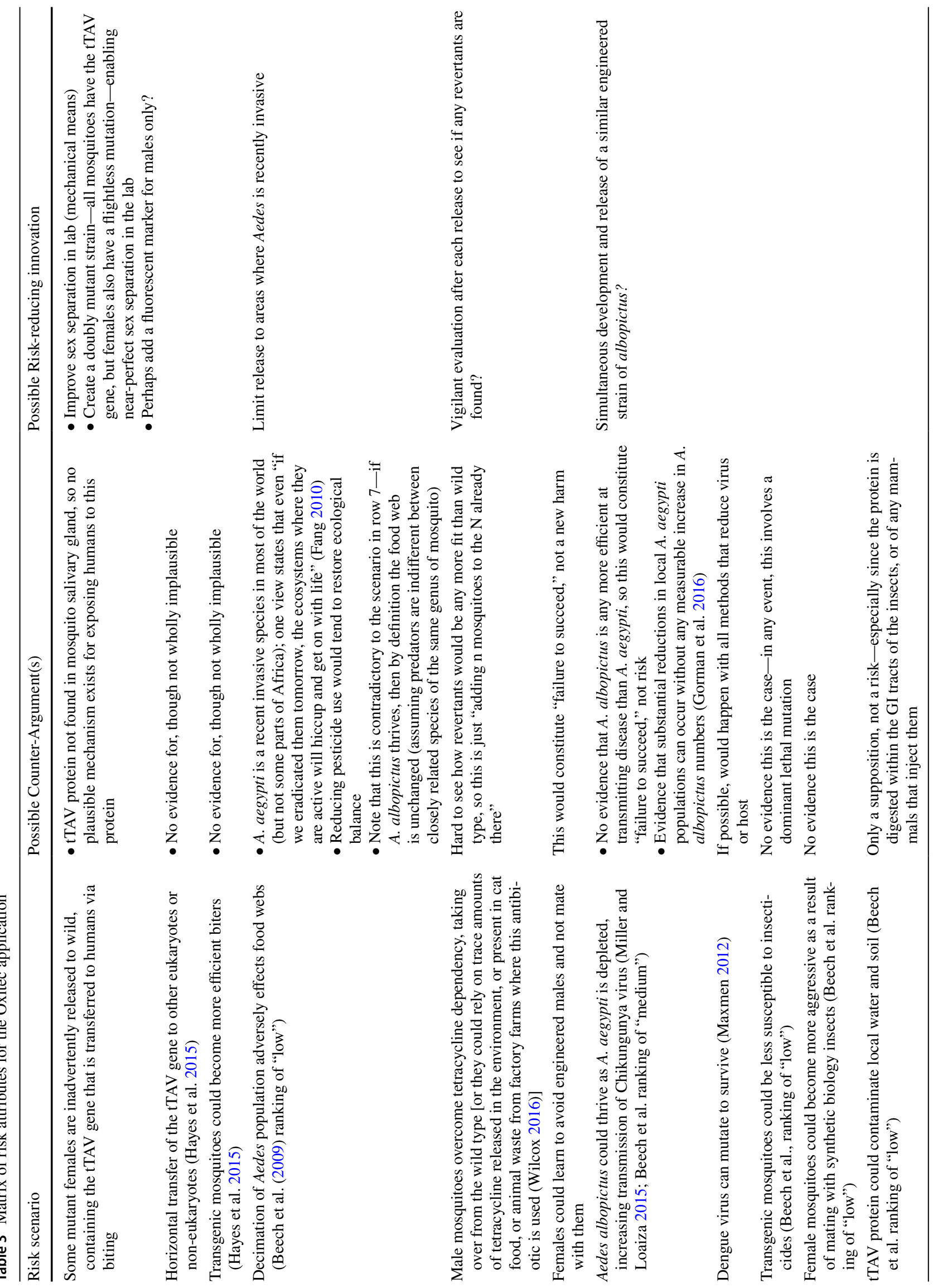


finding by the U.S. Food and Drug Administration (FDA) that an environmental impact statement was not needed for a planned release of the Oxitec mosquitoes-was buttressed only by a conclusory statement that the scenarios discussed below were individually and cumulatively of no significant concern for human health or the environment (FDA 2016). So we used for much of the raw material for Table 3 the results from the two true risk assessments we were able to find (Beech et al. 2009; Hayes et al. 2015). Both have deficiencies for this purpose: the former analysis is only semiquantitative and the latter, while quite sophisticated and quantitative, deals not directly with the Oxitec application, but with the engineering of sterile male Anopheles gambiae mosquitoes.

The Beech et al. assessment used a structured expert elicitation, involving 70 experts over a 3-day period, to characterize 31 different risk scenarios as posing one of four different levels of risk (negligible, low, medium, or high—although the last adjective appears nowhere in the assessment as none of the risks were graded as higher than "medium"). The authors emphasize that they did not attempt to elicit separate gradings for probability and for consequence of each scenario, but that the experts factored both of these fundamental aspects of risk into the appraisals. Of the 31 scenarios, 26 were rated as "negligible," four as "low," and one as "medium." Table 3 discusses the five scenarios ranked as non-negligible.

The CSIRO assessment is, in some respects, favorably comparable to conventional and robust risk assessments, including the chemical and especially the carcinogenic risk assessments that are the most well-developed arena in this field. Based on a systematic literature review, aided by "hierarchical holographic modeling" (basically, arraying hundreds of possible risk scenarios into a pairwise matrix corresponding to elements of the ecosystem and of human health, and then finding repeating commonalities among the scenarios), the CSIRO team identified five risky scenarios where QRA would be most needed to gauge the overall probability and severity of adverse outcomes, and, to some extent, where QRA would also be most tractable. The researchers (Hayes et al., p. 98) took a strong position that quantification - with due respect for uncertainty-is inherently superior to any more impressionistic method:

This risk assessment was designed to be scientific, honest and conservative. The assessment quantifies the risk of a set of endpoints that were carefully chosen to minimize the complexity of the assessment without compromising its relevance to decision-makers and stakeholders. The assessment maintains transparency, and coherently propagates uncertainty through its calculations, by quantifying risks, adhering to the laws of probability theory and avoiding qualitative risk assertions.

In keeping with this orientation, they went to admirable lengths to quantify the probability of each hazardous endpoint; they undertook a structured expert elicitation involving 24 experts asked to provide central estimates and uncertainty bounds for the parameters needed to operationalize more than 1000 fault-tree pathways, which CSIRO then combined into probability distributions for each of the five key endpoints:

1. An unexpected increase in the malaria-transmission capacity of modified mosquitoes;

2. Transmission of a novel bloodborne pathogen from $A n$. gambiae to humans;

3. Spread of the gene causing sterility (the "I-Ppol homing endonuclease gene," found in a slime mold) into eukaryotes other than An. gambiae;

4. Spread of I-Ppol into one or more non-eukaryotes; and

5. Spread of I-Ppol throughout the An. gambiae population, rather than it staying confined within the first generation released into the environment.

The researchers used some of the techniques pioneered in elicitation methods for chemical risks; for example, they imposed some probabilistic dependencies between certain responses each expert gave and subsequent responses, in effect prodding the subjects to answer in ways that were somewhat constrained by logic, when appropriate (Evans et al. 1994). They also presented probability estimates using two thoughtful ways of combining disparate judgments among experts, either creating inter-expert probability distributions for each uncertain parameter in each risk scenario, and then propagating these distributions through functional models relating the parameters to each other, or alternatively by creating an output probability distribution for risk for each expert, and then describing the mean and variance of the inter-expert judgments. In addition, the CSIRO group grappled with the perennial problem of how to estimate the probability of an event that has never occurred, given an estimate of how many times the event could have occurred but has not (Kousky et al. 2010). They call this the "nullevent inference" issue, and present a spectrum of computational methods to handle this problem that generally yield comparable results.

However, the null-event calculations are nowhere integrated into the main results from the elicitations. It appears (see Hayes et al., p. 80) that the expert confidence interval for one particular risk - the probability that the I-Ppol gene will spread into wild-type An. gambiae mosquitoes-extends beyond the upper confidence limit derived from null-event theory, which may be seen as a desired result. The experts 
here were not swayed by the fact that the "best estimate" of this probability based on null past events was zero.

Table 7.1 in the CSIRO report (p. 100) shows how careful risk assessment can provide useful estimates, with uncertainty, of the probability that each of several untoward events from a deliberate environmental release of a synthetic biology application can occur. For each of the five scenarios, the table gives a median, upper 90th percentile, and upper 99th percentile probability estimate, generally but not exclusively relying on the first of the two inter-expert aggregation methods described above. For example, the median estimate of the probability of the second scenario mentioned in the list above (transmission of a novel bloodborne pathogen to humans) was estimated at $5.2 \times 10^{-7}$, with a worst-case probability of $4.6 \times 10^{-3}$. The researchers concluded (p. 4) that "the risks of the first, second, third and fourth endpoints are sufficiently remote so as not to warrant any additional specific risk mitigation at this stage in the development pathway," and that the fifth scenario (spread of I-Ppol to wildtype An. gambiae mosquitoes) is sufficient to warrant the risk mitigation strategies that are currently being planned by the Target Malaria consortium, where the worst-case probability of this endpoint was estimated at one chance in five.

However, it is important to note (CSIRO, p. 3) that "this endpoint is not a pre-cursor to a harmful event, indeed reducing populations of species in the An. gambiae complex is one way to reduce the transmission of the malaria parasite. This endpoint is, however, considered undesirable at this stage of the development pathway of this new genetic technology because the current construct is supposed to be inherently self-limiting." In other words, the scenario with the least-unlikely occurrence probability is actually not a risk, but more like an "unexpected event with no clear harm"- and it could even be viewed as a fortuitous success of the application.

As much of an advance as the CSIRO report clearly is in quantifying synthetic biology risk probabilities, unfortunately it essentially punts on the other half of the coin, and sheds no quantitative light on the severity of any of the endpoints analyzed. To be sure, it would have been hard for the group to quantify any severities, because they made their probability estimates more useful by aggregating several closely related outcomes under each of the five scenarios-for each of the entries in CSIRO Table 7.1, there are several different levels of harm subsumed within the scenario. Nevertheless, it is hard to know what to make of a result that "using worst-case thinking, the chance of a novel bloodborne pathogen being transmitted to humans by synthetic biology mosquitoes is 1 in 200," when there is no discussion of the consequences if this non-trivial probability became a reality.

\subsection{Synthetic biology risk communication}

The prospect of a local release of synthetic biology mosquitoes has aroused considerable opposition in some of the communities where Oxitec has sought to conduct field trials, notably the Florida Keys (Alvarez 2016). Such releases implicate all of the well-known ideological and cognitive factors, including dread, unfamiliarity, involuntariness, and moral unease with genetic modification, that may cause opponents of a synthetic biology application like Oxitec's to focus on ill-defined scenarios of harm and perhaps to insufficiently consider the ongoing harms of conventional methods and the harms of inaction (Slovic 1987; Alvarez 2016). Notably, Alvarez (2016) quotes a Key Haven resident as saying "People here can survive what nature throws at them... Hurricanes, bring them on; long-timers here seldom evacuate. Mosquitoes, well, that's the price of paradise. Zika, this too shall pass, like dengue. But science and government, I'm not so sure about"- -suggesting that in some cases, affected citizens prefer "natural" hazards to technological remedies.

In addition to the inherent risk communication problems, though, the developers here have not always communicated well with their stakeholders. In several locales, Oxitec has announced an impending release of its mosquitoes, rather than working with local citizens to explain the immediate benefits or to optimize the particulars of the trial. It also may have made itself vulnerable to concerns over misleading disclosures, by referring to its male mosquitoes as "sterile." More correctly, of course, the whole point of the application is that the males are fertile, but produce offspring who die before they are mature enough to bite humans. This distinction is largely semantic and, as Oxitec has said, "there is no layman's term for 'passes on an autocidal gene that kills offspring'." However, those who oppose the approach and/ or the technology do tend to seize on these kinds of discrepancies (Specter 2012). It probably also does not help reach informed consensus-or at least to reach reluctant acceptance-when proponents of the application bridge fundamental uncertainties about untoward effects with logic that may well seem cavalier. It is one thing, for example, to say that A. aegypti mosquitoes are recently invasive in an area, and that there is no direct evidence that an ecosystem would not quickly adapt to their absence, but another to cite as evidence for the same proposition that "if there was a benefit to having them [mosquitoes] around, we would have found a way to exploit them" (Fang 2010, quoting an official from the U.S. Centers for Disease Control and Prevention).

It is difficult, however, to have a dialogue about the degree of risk, and the appropriate precautions to take, in the proverbial empty auditorium. In chemical risk assessment, there is a small literature documenting the long-standing reluctance of environmental activists to engage with government and industry so as to improve the accuracy and enable 
the precautionary interpretation of risk estimates (Tal 1997). This reluctance has at times yielded risk-based decisions that were insufficiently "conservative" in the face of uncertainty, when mutual discussions might have resulted in decisions even more precautionary than successful insistence on "zero risk" would have, because banning something may result in a net risk increase when the substitute activity is considered.

There are echoes of this hands-off attitude in some of the recent reports on the governance of synthetic biology insects, notably the 2015 report from the UK House of Lords, which welcomed oral and written commentary and heard from about 35 individuals and groups, but specifically noted (House of Lords 2015):

"surprise and regret that individuals and groups who are sceptical of the merits of GM [genetic modification] technologies did not engage with our inquiry. No written submissions were received from groups known for their concerns about GM, and there was seemingly little appetite from them to give oral evidence to us. There was, of course, no obligation on this community to engage with our inquiry. Nevertheless, it was puzzling that they did not wish for their voices to be heard." (p 6).

\section{Conclusions}

We believe that SFRA offers a new and useful way to think about the vexing question of whether government should take a precautionary or a "permissionless" (Thierer 2016) stance towards emerging technologies. This is not necessarily an either/or choice-after all, government can evaluate new technologies before they are fully scaled in the market, but can take a highly risk-averse stance towards novel risks or a highly benefit-seeking stance towards new opportunities for risk reduction. But within its wide latitude to grant permission (Kaebnick and Gusmano 2018) with little or intense scrutiny and burdens of proof, SFRA offers decision-makers a systematic way to pose more useful questions than "is the new technology 'safe'?"

When applied to the question of whether a new technology is a superior solution to an ongoing risk, the version of SFRA explained here seeks to estimate, with uncertainty, the magnitude of expressions of the form $\left[\left(R_{1 c}+R_{2 c}\right)-\left(R_{1 s}+R_{2 s}\right)\right]$, where the subscripts "c" and "s" refer, respectively, to a conventional solution and a synthetic biology application, the subscripts " 1 " refer to the risks remaining after a technology has partially controlled the ongoing risk, and the subscripts " 2 " refer to new risks added by a given technology. If this expression has a positive expected value, then the synthetic biology application can be said to offer (on average) a net risk-improving contribution to the status quo., Of course, if uncertainty is also considered, the expression can acknowledge both the probability and magnitude of the risk-improving prospects as well as any downside chances that the new technology will be a risk-increasing change to the status quo.

A more complete description of how analysts and decision-makers might collaborate to perform a solution-focused risk assessment for a suite of conventional and synthetic biology approaches to a problem, and how the results of the assessment might be used to design regulations, information-disclosure campaigns, or various "soft law" interventions, is provided in Finkel (2018). Here we merely address one fundamental objection to the very activity of comparing the risk profiles of different products/technologies: that acting on the results of the comparison amounts to society "picking winners and losers" rather than letting the market do so. Indeed, while we regard the question "is it safer?" to be a more sensible one than "is it safe?", others (see, e.g., Mannix 2018) complain that at most, government should confine its interventions to cases where a new technology is not safe or effective in absolute, not relative terms. We cannot resolve this controversy here, but simply note that (1) government erects barriers to new technologies all the time, particularly by providing subsidies to established technologies (Roberts 2016); and (2) because the risk-reducing and risk-creating powers technologies have are often far harder for society to discern and weigh than the market attributes of these technologies (e.g., cost, usefulness, taste, appearance), the free market is often incapable of favoring "winners" that truly provide welfare-increasing results. While this profound policy controversy continues, we believe that identifying superior solutions to technologies that address identical problems cannot help but enrich the discussion.

Considering various conventional and synthetic biology options for dengue vector control, the risk-reduction half of the SFRA comparison here involves juxtaposing the lackluster track record of conventional approaches against dengue - physical barriers such as mosquito bed nets that lack efficacy against $A$. aegypti (which tends to bite during daylight hours), chemical pesticides (which tend to engender resistance), irradiation to sterilize male mosquitoes (often rendering them less fit to compete with wild-type males in mating), and human vaccines (which have not yet been made effective)—with the promising but preliminary results (up to $90 \%$ reduction of mosquito larvae in a defined area within weeks of the release of Oxitec mosquitoes) from the synthetic biology alternative.

The risk-increasing half of the SFRA comparison involves juxtaposing the known risks of conventional methods-particularly the well-characterized human health and ecological damage from pesticides, and the risk of 
ecological disruption following introduction of novel predators such as water bugs to prey on mosquitoes-against the various risky scenarios described in the Beech et al. (2009) and Hayes et al. (2015) assessments. Although we emphasize that the latter risks are not yet quantitatively characterized adequately, we tentatively suggest that all in all, they may have a longer right-hand tail (reasonable worst-case) than the conventional risks, but a smaller expected magnitude. The Oxitec application, therefore, may have greater risk-reduction potential, as well as smaller risk-increasing potential, than previous methods that have tried to stem the tide of dengue fever. Future research should concentrate on making the risk-risk comparisons more quantitative, more integrative (summing risks across disparate scenarios), and more robust, and also on exploring hybrid strategies that might make use of a thoughtful combination of the synthetic biology approach and one or more conventional methods, to increase the net risk-reducing profile of the initiatives.

Further, among the non-traditional options the Oxitec solution is particularly appealing because, arguably, the developers have sought out the "sweet spot" where the hybrid organism created is neither too weak to compete successfully with wild-type males, as irradiated male mosquitoes can be, nor any in way more fit than the wild type, an outcome that would raise many legitimate concerns about introducing inherently risky organisms into the environment. So it may be more apt to think of conventional methods as having analogous environmental, public health, and occupational harms to those of coal, oil, and natural gas, and the Oxitec method as perhaps akin to an "inherently safe" nuclear reactor, though safer with respect to "meltdowns," not necessarily with respect to long-term consequences of "disposal."

The coal/nuclear analogy may be unfairly pessimistic with respect to synthetic biology in one important respect: while both sources of energy can be made roughly equivalent in efficacy (energy production), conventional methods of dengue control clearly lack the efficacy we desire. If the synthetic biology risk portfolio was roughly equal to that of conventional methods, therefore, society might well favor the former as a risk-neutral, but benefit-improving, step change.

And there are some reasons, despite the many knowledge gaps in the quantitative risk comparison, to believe that the Oxitec risk portfolio may indeed compare favorably, considering both its central tendency and its right-hand tail, to that of conventional methods. Our overall impression is that the Oxitec risk portfolio consists of three distinct categories of concern:

- Various low-probability risks to human health whose severity has not been well characterized, but for which few plausible logic models and pathways exist under which the outcomes would be substantially more dire than the health risks we already bear from the conventional approaches to dengue control;

- Various low-probability risks to ecosystems and food webs whose severity has not been well characterized, but for which few plausible logic models exist under which the outcomes would be substantially more dire than the ecosystem risks we already bear from the conventional approaches to dengue control; and

- Various moderately high-probability risks, but ones that are more properly characterized as "failures to succeed"- - untoward outcomes that will be disappointing, especially to the developers who will bear the financial costs of failure, because they would take mosquito control back to the status quo ante, but that will leave behind no significant new risks.

Considering all that is known and not known about the conventional portfolio of controls and the Oxitec application, the synthetic biology approach may be worth attempting. The basic logic behind this statement is that the uncertainty distribution for the quantity $\left[\left(\mathrm{R}_{1 \mathrm{c}}+\mathrm{R}_{2 \mathrm{c}}\right)-\left(\mathrm{R}_{1 \mathrm{~s}}+\mathrm{R}_{2 \mathrm{~s}}\right)\right]$ - the dengue risk remaining after conventional controls have been applied, plus the new risks of conventional controls, compared to the same two entries for the synthetic biology method-may well have a positive expected value. In other words, the geographic area targeted for intervention with Oxitec mosquitoes in it may on average be less risky than the area with conventional controls unleashed against mosquitoes. The quantity $\left[\left(\mathrm{R}_{1 \mathrm{c}}+\mathrm{R}_{2 \mathrm{c}}\right)-\left(\mathrm{R}_{1 \mathrm{~s}}+\mathrm{R}_{2 \mathrm{~s}}\right)\right]$ may have a tail that extends to the negative region-where switching to synthetic biology controls may make the risk profile worse than before-but this case study suggests that the tail risks may be less important, in terms of the length of the tail and the probability underneath the tail, than the more likely outcome of decreased total risk.

We emphasize, however, that the above is a relative judgment - that Oxitec appears to have a relatively more positive expected value of total risk reduction than several leading approaches currently in use-rather than necessarily having an absolute positive value. Whatever the true distribution of $\left[\left(R_{1 c}+R_{2 c}\right)-\left(R_{1 s}+R_{2 s}\right)\right]$ is, though, it can be made relatively more positive by considering some of the win/ win approaches in Table 3, and by vigilant monitoring of any releases to look for incipient evidence that one or more of the downside scenarios may be occurring.

Finally, another logical approach to trying to shift the uncertainty distribution for the total amount of net risk reduction to the right (more positive) would involve a twophase strategy: using the Oxitec application as a primary control measure, and then seeing if variant forms of some conventional controls might be made more useful, and less risky, when used as "mop-up" tactics against the reduced mosquito population in the target area. Not all of these 
combination strategies make sense: in particular, concerns have been raised about the assumption that imperfect vaccines can be shored up by using traditional vector controls (Paul et al. 2014). But to the extent that some of the conventional controls (e.g., insecticides) have non-linear risk profiles (that is, modest amounts are of far less concern than excessive amounts), they may be excellent complements to a primary strategy that begins with a synthetic biology approach.

Indeed, Oxitec's leaders also suggest that their technology will be only one piece of a disease management system (Alphey et al. 2010). Anthony James of the University of California concurs with this statement, claiming that "don't expect [Oxitec's mosquitoes] will provide the solution alone," and that an aggregation of other components to fight disease and control local mosquito populations is necessary to move closer towards disease eradication (Alphey et al. 2010). These statements reflect the notion that, while Oxitec's synthetic biology alternative to mosquito population control may be effective, it may perform best in tandem with one or more of the other conventional mosquito control technologies.

More so than several of the other synthetic biology applications we have looked into (Finkel 2018), the Oxitec application has, in our view, a comparatively favorable benefit-risk profile. In the other cases, either the marginal benefits compared with existing alternatives are smaller, the marginal risks are greater, or both (see similar discussion of risk, benefit, and commercialization challenges for emerging biotechnologies in Mampuys and Brom (2017)). Nevertheless, deployment of the engineered mosquitoes must be accomplished in a more transparent and precautionary way than has been undertaken to date, with additional realtime evaluation of its continued safety and efficacy and with enhanced public engagement/communication activities.

Acknowledgements The authors gratefully acknowledge a generous grant from the Alfred P. Sloan Foundation (Grant G-2013-3-03), which supported this research and other work related to comparative risk assessment and governance of synthetic biology applications, and appreciate the helpful comments from three anonymous reviewers.

\section{References}

Aguiar M, Halstead SB, Stollenwerk N (2017) Consider stopping dengvaxia administration without immunological screening. Expert Rev Vaccines 16(4):301-302

Aguiar M (2018) Dengue vaccination:a more ethical approach is needed. The Lancet 391:1769-1770

Alphey L, Benedict M, Bellini R, Clark GG, Dame DA, Service MW, Dobson SL (2010) Sterile-insect methods for control of mosquito-borne diseases: an analysis. Vector-Borne Zoonotic Dis 10:295-311
Alvarez L (2016), Florida keys, some worry about 'science and government' more than Zika. New York Times, p A9

Bachou H, Tylleskär T, Kaddu-Mulindwa DH, Tumwine JK (2006) Bacteraemia among severely malnourished children infected and uninfected with the human immunodeficiency virus-1 in Kampala, Uganda. BMC Infect Dis 6:160

Bates ME, Grieger KD, Trump BD, Keisler JM, Plourde KJ, Linkov I (2015) Emerging technologies for environmental remediation: integrating data and judgment. Environ Sci Technol 50(1):349-358

Beech CJ, Nagaraju J, Vasan SS, Rose RI, Othman RY, Pillai V, Saraswathy TS (2009) Risk analysis of a hypothetical open field release of a self-limiting transgenic Aedes aegypti mosquito strain to combat dengue. Asia Pac J Mol Biol Biotechnol 17:99-111

Bhatt S, Gething PW, Brady OJ, Messina JP, Farlow AW, Moyes CL, et al (2013) The global distribution and burden of dengue. Nature 496:504-507

BioSpectrum. Inviragen DENVax dengue vaccine shows promise. https ://www.biospectrumasia.com/news/37/2578/inviragen-denva x-dengue-vaccine-shows-promise-.html. Accessed 9 May 2018

Brown AW (1986) Insecticide resistance in mosquitoes: a pragmatic review. J Am Mosq Control Assoc 2:123-140

Butler K (2012) Can GMO mosquitoes save you from dengue? Mother Jones. https://www.motherjones.com/environment/2012/05/genet ically-engineered-mosquitoes-oxitec/. Accessed 9 May 2018

Canyon DV, Hii JLK, Muller R (1999) Effect of diet on biting, oviposition, and survival of Aedes aegypti (Diptera: Culicidae). J Med Entomol 36:301-308

Carter SR, Rodemeyer M, Garfinkel MS, Friedman RM (2014) Synthetic biology and the US Biotechnology Regulatory System: challenges and options (No. DOE-JCVI-SC0004872). J. Craig Venter Institute, Rockville, Maryland

CDC. Symptoms and what to do if you think you have dengue. http:// www.cdc.gov/dengue/Symptoms/. Accessed 9 May 2018

Clark DV, Mammen MP Jr, Nisalak A, Puthimethee V, Endy TP (2005) Economic impact of dengue fever/dengue hemorrhagic fever in Thailand at the family and population levels. Am J Trop Med Hyg 72:786-791

Clarke T (2002) Dengue virus: break-bone fever. Nature 416:672-674

Clean Air Task Force (2010) The toll from coal: an updated assessment of death and disease from America's Deadliest Energy Source. http://www.catf.us/resources/publications/files/The_ Toll_from_Coal.pdf. Accessed 9 May 2018

CNN Philippines Staff (2018). Timeline: the Dengvaxia controversy. February 26, Available at http://cnnphilippines.com/ news/2017/12/09/The-Dengvaxia-controversy.html

Cobra C, Rigau-Pérez JG, Kuno G, Vomdam V (1995) Symptoms of dengue fever in relation to host immunologic response and virus serotype, Puerto Rico, 1990-1991. Am J Epidemiol 142:1204-1211

Cole GT, Hoch HC (eds) (1991) The fungal spore and disease initiation in plants and animals. Springer, New York

Coller BAG, Clements DE (2011) Dengue vaccines: progress and challenges. Curr Opin Immunol 23:391-398

Cox LA (2008) What's wrong with risk matrices? Risk Anal 28(2):497-512

Daghrir R, Drogui P (2013) Tetracycline antibiotics in the environment: a review. Environ Chem Lett 11(3):209-227

Dame DA, Curtis CF, Benedict MQ, Robinson AS, Knols BGJ (2009) Historical applications of induced sterilisation in field populations of mosquitoes. Malar J 8:S2

Dengue Vaccine Initiative. Vaccine development. http://www.dengu evaccines.org/vaccine-development. Accessed 9 May 2018

Dutra HLC, Rocha MN, Dias FBS, Mansur SB, Caragata EP, Moreira LA (2016) Wolbachia blocks currently circulating Zika virus 
isolates in brazilian Aedes aegypti mosquitoes. Cell Host Microbe 19:771-774

Endy TP, Nisalak A, Chunsuttiwat S, Libraty DH, Green S, Rothman AL et al (2002) Spatial and temporal circulation of dengue virus serotypes: a prospective study of primary school children in Kamphaeng Phet, Thailand. Am J Epidemiol 156:52-59

Environmental Protection Agency. Pesticides. http://www.epa.gov/ pesticides/health/reducing.htm. Accessed 9 May 2018

Evans JS, Graham JD, Gray GM, Sielken RJ Jr (1994) A distributional approach to characterizing low-dose cancer risk. Risk Anal 14:25-34

Fang J (2010). Ecology: a world without mosquitoes. Nature 466:432-434

FAO/IAEA/USDA (2003). Manual for product quality control and shipping procedures for sterile mass-reared tephritid fruit flies, Version 5.0. International Atomic Energy Agency, Vienna, p 85

Finkel AM (2011) Solution-focused risk assessment: a proposal for the fusion of environmental analysis and action. Hum Ecol Risk Assess 17(4):754-787 (and 5 concurrent responses/commentaries, pp. 788-812)

Finkel AM (2018) Designing a 'solution-focused' governance paradigm for synthetic biology: case studies of improved risk assessment and creative regulatory design. Forthcoming report to the Alfred P. Sloan Foundation

Finkel AM, Gray G (2018) Taking the reins: how regulatory decisionmakers can stop being hijacked by uncertainty. Environ Syst Decis. https://doi.org/10.1007/s10669-018-9681-x

Follett PA, Duan JJ (eds). (2012). Nontarget effects of biological control. Kluwer Academic Publishers, Dordrecht

Food and Drug Administration, U.S. (2016). Environmental Assessment for Investigational Use of Aedes aegypti OX513A. August 5, p 138, Available at https://www.fda.gov/downloads/Anima IVeterinary/DevelopmentApprovalProcess/GeneticEngineering/ GeneticallyEngineeredAnimals/UCM514698.pdf)

Fu G, Lees RS, Nimmo D, Aw D, Jin L, Gray P et al (2010). Femalespecific flightless phenotype for mosquito control. Proceed Natl Acad Sci 107:4550-4554

Genetic Engineering and Biotechnology News (2014) Sanofi Pasteur Dengue Vaccine Aces Second Phase III Trial. http://www.genen gnews.com/gen-news-highlights/sanofi-pasteur-dengue-vacci ne-aces-second-phase-iii-trial/81250300/. Accessed 9 May 2018

Gentzel M et al (2016) Comments to FDA on draft environmental assessment and preliminary finding of no significant impact concerning investigational use of Oxitec OX513A mosquitoes. p 12, Available at http://signaldatascience.com/projects/mattgentzel/ EAPASubmissiononOX513AMosquitoes.pdf

Gladwell M (2001) The mosquito killer. The New Yorker, July 2, p 42

GM Watch (2014) Lack of risk assessment for GM mosquito experiments is negligent. http://www.gmwatch.org/index.php/news/ archive/2014/15301-lack-of-risk-assessment-for-gm-mosquitoexperiments-is-negligent. Accessed 9 May 2018

Gorman K et al (2016) Short-term suppression of Aedes aegypti using genetic control does not facilitate Aedes albopictus. Pest Manag Sci 72(3):618-628

Grady D, Thomas K (2017) Drug company under fire after revealing dengue vaccine may harm some. New York Times, December 17. https://www.nytimes.com/2017/12/17/health/sanofi-dengu e-vaccine-philippines.html. Accessed 9 May 2018

Guarino B (2016). Like it's been nuked: Millions of bees dead after South Carolina sprays for Zika mosquitoes. Washington Post, Sept 1. Available at https://www.washingtonpost.com/news/ morning-mix/wp/2016/09/01/like-its-been-nuked-millions-ofbees-dead-after-south-carolina-sprays-for-zika-mosquitoes/
Gubler DJ (2010) Dengue viruses. In: Mahy BWJ, Van Regenmortel MHV (eds) Desk encyclopedia of human and medical virology. Academic Press, Boston, pp 372-382

Guy B, Barrere B, Malinowski C, Saville M, Teyssou R, Lang J (2011) From research to phase III: preclinical, industrial and clinical development of the Sanofi Pasteur tetravalent dengue vaccine. Vaccine 29:7229-7241

Guzman MG, Halstead SB, Artsob H, Buchy P, Farrar J, Gubler DJ et al (2010) Dengue: a continuing global threat. Nat Rev Microbiol 8:S7-S16

Harris AF, Nimmo D, McKemey AR, Kelly N, Scaife S, Donnelly CA, Alphey L (2011) Field performance of engineered male mosquitoes. Nat Biotechnol 29:1034-1037

Harris AF, McKemey AR, Nimmo D, Curtis Z, Black I, Morgan SA et al (2012) Successful suppression of a field mosquito population by sustained release of engineered male mosquitoes. Nat Biotechnol 30:828-830

Harvey C (2016). A shocking one-third of Americans believe this Zika conspiracy theory. Washington Post. Retrieved from https://www. washingtonpost.com/news/energy-environment/wp/2016/02/23/ a-shocking-one-third-of-americans-believe-this-zika-conspiracy -theory/?utm_term=.b924cda8e2b5. For more information on the Annenberg Public Policy Center survey instrument itself, see http://www.annenbergpublicpolicycenter.org/wp-content/uploa ds/ZikaWeek1 Appendix.pdf

Hassenzahl D, Finkel AM (2008). Risk assessment for environmental and occupational health. In: Heggenhougen K, Quah S (eds), International encyclopedia of public health. Elsevier Inc., London, pp 590-600

Hayes KR, Barry S, Beebe N, Dambacher JM, De Barro P, Ferson S et al (2015) Risk assessment for controlling mosquito vectors with engineered nucleases: sterile male construct: final report. CSIRO Biosecurity Flagship, Hobart. https://publications.csiro .au/rpr/pub?pid=csiro:EP153254. Accessed 9 May 2018

Hotez PJ, Fenwick A, Savioli L, Molyneux DH (2009) Rescuing the bottom billion through control of neglected tropical diseases. Lance 373:1570-1575

House of Lords, Parliament of the United Kingdom, Science and Technology Select Committee (2015). Genetically modified insects, London, p 58, Dec 17, (quoted material at page 14), Available at http://www.publications.parliament.uk/pa/ld201516/ldselect/ ldsctech/68/68.pdf

Hull K. (2006). Malaria: fever wars. PBS Documentary

Institute of Physics (2010) Science, technology and innovation for poverty Reduction, http://www.iop.org/publications/iop/2009/ file_44076.pdf

Kaebnick GE, Gusmano MK (2018) Making policies about emerging technologies. Hastings Cent Spec Rep 48(1):S2-S11. Available at https://www.thehastingscenter.org/publications-resources/ special-reports-2/governance-emerging-technologies-aligningpolicy-analysis-publics-values/. Accessed 9 May 2018

Kaplan S, Garrick BJ (1981) On the quantitative definition of risk. Risk Anal 1(1):11-27

Klassen W (2009) Introduction: development of the sterile insect technique for African malaria vectors. Malar J. https://doi. org/10.1186/1475-2875-8-S2-I1

Kousky C, Pratt J, Zeckhauser R (2010). Virgin versus experienced risks. Chapter 11 in the irrational Economist, Michel-Kerjan E, Slovic P (eds), Public Affairs Press, New York, pp 99-106

Krumholz LA (1948) Reproduction in the western mosquitofish, Gambusia affinis affinis (Baird \& Girard), and its use in mosquito control. Ecol Monogr 18:1-43

Kuzma J, Tanji T (2010) Unpackaging synthetic biology: Identification of oversight policy problems and options. Regul Gov 4(1):92-112 
Lave LB, Freeburg LC (1973) Health effects of electricity generation from coal, oil, and nuclear fuel. Nucl Saf 14:409-428

Le Prince JAA (1915) The lethal ovitrap: a response to the resurgence of dengue and chikungunya. Public Health Rep 30:4-11

MacIntyre CR, Engells TE, Scotch M, Heslop DJ, Gumel AB, Poste G et al (2017). Converging and emerging threats to health security. Environment Systems and Decisions, pp 1-10

Malaria Site. Efforts of malaria control. http://www.malariasite.com/ history-control/. Accessed 9 May 2018

Malloy T, Trump BD, Linkov I (2016). Risk-based and preventionbased governance for emerging materials. Environ Sci Technol 50:6822-6824

Malloy T, Zaunbrecher V, Beryt E, Judson R, Tice R et al (2016) Advancing alternatives analysis: the role of predictive toxicology in selecting safer chemical products and processes. Integr Environ Assess Manag 13(5):915-925

Mampuys R, Brom F (2017) Emerging crossover technologies: how to organize a biotechnology that becomes mainstream? Environ Syst Decis. https://doi.org/10.1007/s10669-017-9666-1

Mannix B (2018) Benefit-cost analysis and emerging technologies. Hastings Cent Spec Rep 48(1):S12-S20. Available at https:// www.thehastingscenter.org/publications-resources/special-repor ts-2/governance-emerging-technologies-aligning-policy-analy sis-publics-values/. Accessed 9 May 2018

Maxmen A (2012) Florida abuzz over mosquito plan. Nature 487:286

Mendes H (2012) Brazil tests GM mosquitoes to fight dengue. Nature News. https://www.nature.com/news/brazil-tests-gm-mosquitoes -to-fight-dengue-1.10426. Accessed 9 May 2018

Miller MJ, Loaiza JR (2015) Geographic expansion of the invasive mosquito Aedes albopictus across Panama-implications for control of dengue and chikungunya viruses. PLOS Negl Trop Dis $1-7$

Moreira LA, Iturbe-Ormaetxe I, Jeffery JA, Lu G, Pyke AT, Hedges LM et al (2009) A wolbachia symbiont in aedes aegypti limits infection with dengue, chikungunya, and plasmodium. Cell 139:1268-1278

Müller P (1995) DDT the insecticide dichlorodiphenyl-trichloroethane and its significance/Das Insektizid Dichlordiphenyl-trichlorathan und seine Bedeutung. Springer, Basel

National Research Council (1983) Risk assessment in the Federal Government: managing the process. National Academy Press, Washington, DC

National Research Council (2009) Science and decisions: advancing risk assessment. National Academy Press, Washington, DC, see Chap. 9

Natural News. UK company Oxitec plans to release GM mosquitoes in Panama without required risk assessment. http://www.natur alnews.com/044024_gm_mosquitoes_risk_assessment_oxite c.html. Accessed 9 May 2018

Navarro A (2016) Larvicide manufactured by Sumitomo, not Zika virus, true cause of brazil's microcephaly outbreak: doctors. http://www.techtimes.com/articles/133548/20160214/monsa nto-larvicide-not-zika-virus-true-cause-of-brazils-microcepha ly-outbreak-doctors.htm. Accessed 9 May 2018

Normile D (2013) Surprising new dengue virus throws a spanner in disease control efforts. Science 342:415

Ooi E-E, Goh K-T, Gubler DJ (2006) Dengue prevention and 35 years of vector control in Singapore. Emerg Infect Dis 12:887-893

Ostera GR, Gostin LO (2011) Biosafety concerns involving genetically modified mosquitoes to combat malaria and dengue in developing countries. J Am Med Assoc 305:930-931

Oxitec. FAQs. https://www.oxitec.com/faq/. Accessed 9 May 2018

Oxitec. Our Technology. https://www.oxitec.com/our-technology/. Accessed 9 May 2018

Oye KA, Esvelt K, Appleton E, Catteruccia F, Church G, Kuiken T et al (2014) Regulating gene drives. Science 345(6197):626-628
Palma-Oliveira JM, Trump BD, Wood MD, Linkov I (2017) Community-driven hypothesis testing: a solution for the tragedy of the anticommons. Risk Anal 38:620-634

Paoli G, Wiles A (2015) Key analytical capabilities of a best-in-class regulator. Research paper prepared for the Penn Program on Regulation's Best-in-Class Regulator Initiative, p 54. Available at https://www.law.upenn.edu/live/files/4710-paoliwiles-ppr-resea rchpaper062015pdf. Accessed 9 May 2018

Paul R, Sousa C, Sakuntabhai A, Devine G (2014) Mosquito control might not bolster imperfect dengue vaccines. Lancet $384: 1747-1748$

Pollack A (2011) Concerns are raised about genetically engineered mosquitoes. The New York Times

Pollack A (2016) New weapon to Fight Zika: the mosquito. New York Times, January 31. http://www.nytimes.com/2016/01/31/busin ess/new-weapon-to-fight-zika-the-mosquito.html. Accessed 9 May 2018

PR Newswire (2014) Panama says 'go' to GM mosquito evaluation, Jan. 28. https://www.prnewswire.com/news-releases/ panama-says-go-to-gm-mosquito-evaluation-242371851.html. Accessed 9 May 2018

Ranjit S, Kissoon N (2011) Dengue hemorrhagic fever and shock syndromes. Pediatr Crit Care Med 12:90-100

Ranson H, Rossiter L, Ortelli F, Jensen B, Wang X, Roth C et al (2001) Identification of a novel class of insect glutathione S-transferases involved in resistance to DDT in the malaria vector Anopheles gambiae. Biochem J 359:295-304

Reiter P, Amador MA, Anderson RA, Clark GG (1995) Short report: dispersal of Aedes aegypti in an urban area after blood feeding as demonstrated by rubidium-marked eggs. Am J Trop Med Hyg $52: 177-179$

Reynolds JL (2016) Same area where gm mosquitoes were released in 2015 is the epicenter for the zika Outbreak. Natural News. Available at http://www.naturalnews.com/052836_Zika_virus _GM_mosquitoes_Brazil.html. Accessed 9 May 2018

Risk Bites (2018) How can solution focused risk assessment help govern emerging technologies? https://www.youtube.com/ watch?v=n7XkdbpYWHk. Accessed 9 May 2018

Roberts TM (2016) Picking winners and losers: a structural examination of tax subsidies to the energy industry. Columbia J Environ Law 41:63-137

Rowe DF (2014). Banned: a history of pesticides and the science of toxicology. Yale University Press, New Haven

Seager TP, Trump BD, Poinsatte-Jones K, Linkov I (2017) Why Life Cycle assessment does not work for synthetic biology. Environ Sci Technol 51(11):5861-5862

Silva Loreto EL, Wallau GL (2016) Risks of Wolbachia mosquito control. Science 351:1273

Simmons CP, Farrar JJ, Nguyen VV, Wills B (2012) Dengue. N Engl J Med 366:1423-1432

Slovic P (1987) Perception of risk. Science 236:280-285

Specter M (2012) The mosquito solution. The New Yorker, July 9

Stearns SC, Sage RD (1980) Maladaptation in a marginal population of the mosquito fish, Gambusia affinis. Evolution 34:65-75

Tal A (1997). A failure to engage. The Environmental Forum, pp 13-21

Thierer A (2016) Permissionless innovation: the continuing case for comprehensive technological freedom. George Mason University, Arlington. https://www.mercatus.org/system/files/ThiererPermissionless-revised.pdf. Accessed 9 May 2018

Trump BD (2017) Synthetic biology regulation and governance: lessons from TAPIC for the United States, European Union, and Singapore. Health Policy 121(11):1139-1146

Trump B, Cummings C, Kuzma J, Linkov I (2017) A decision analytic model to guide early-stage government regulatory action: applications for synthetic biology. Regul Gov 12:88-100 
United States Department of Agriculture (2008) Use of genetically engineered Fruit Fly and Pink Bollworm in APHIS Plant Pest Control Programs. Environmental Impact Statement

VOA. New mosquito nets could help fight malaria in Africa. http:// www.voanews.com/content/a-13-2004-11-23-voa30/30824 0.html. Accessed 9 May 2018

Wallace H (2013) Genetically modified mosquitoes: ongoing concerns. TWN biotechnology and safety series. No. 15. Third World Network, Penang

Waltz E (2016) US reviews plan to infect mosquitoes with bacteria to stop disease. Nature 533:450-451

Webster DP, Farrar J, Rowland-Jones S (2009) Progress towards a dengue vaccine. Lancet Infect Dis 9:678-687

Weill M, Lutfalla G, Mogensen K, Chandre F, Berthomieu A, Berticat $\mathrm{C}$ et al (2003) Comparative genomics: insecticide resistance in mosquito vectors. Nature 423:136-137

Whitehorn J, Farrar J (2010) Dengue. Br Med Bull 95:161-173

Wilcox C (2016) No, GM mosquitoes didn't start the Zika outbreak. Discover. Retrieved from http://blogs.discovermagazine.com/ science-sushi/2016/01/31/genetically-modified-mosquitoes -didnt-start-zika-ourbreak/\#.V6jmhKLdWVc. Accessed 9 May 2018

Williams L (2014) Decoding dengue and West Nile: researchers take steps towards control of growing public health problems. Argonne National Laboratory news release, February
6, http://www.anl.gov/articles/decoding-dengue-and-west-nileresearchers-take-steps-toward-control-growing-public-health. Accessed 9 May 2018

Wise de Valdez MR, Nimmo D, Betz J, Gong HF, James AA, Alphey L, Black WC (2011) Genetic elimination of dengue vector mosquitoes. Proc Natl Acad Sci USA 108:4772-4775

World Health Organization, Comprehensive guidelines for prevention and control of dengue and dengue haemorrhagic fever, 2011. http://apps.searo.who.int/pds_docs/B4751.pdf?ua $=1$. Accessed 9 May 2018

World Health Organization. Dangue vaccine research. http://www. who.int/immunization/research/development/dengue_vaccines/ en/. Accessed 9 May 2018

World Health Organization. Mosquito wars. http://www.who.int/bulle tin/volumes/87/3/09-020309/en/. Accessed 9 May 2018

World Health Organization. Neglected tropical diseases. http://www. who.int/neglected_diseases/diseases/en/. Accessed 9 May 2018

Yakob L, Guiyun Y (2009) Modeling the effects of integrating larval habitat source reduction and insecticide treated nets for malaria control. PLoS ONE 4:e6921

Zambrano L, Martínez-Meyer E, Menezes N, Peterson AT (2006) Invasive potential of common carp (Cyprinus carpio) and Nile tilapia (Oreochromis niloticus) in American freshwater systems. Can J Fish Aquat Sci 63:1903-1910 